\title{
Correction to: Phylogeny and genetic variation in the genus Eranthis using nrITS and cpIS single nucleotide polymorphisms
}

\author{
Seo Young Park ${ }^{1} \cdot$ Mi Jin Jeon ${ }^{1}$. Sang Hoon Ma ${ }^{1}$ Eric Wahlsteen ${ }^{2} \cdot$ Keenan Amundsen ${ }^{3} \cdot \mathrm{Ji} \mathrm{Hee} \mathrm{Kim}^{4}$. \\ Jeung Keun Suh ${ }^{4} \cdot$ Chin-Sung Chang ${ }^{5}$. Young Hee Joung ${ }^{1}$ (i)
}

Published online: 8 May 2019

(c) Korean Society for Horticultural Science 2019

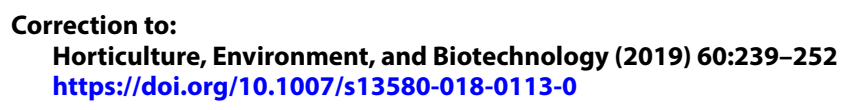

The original version of this article unfortunately contained a mistake. The name of Chin-Sung Chang was presented incorrectly. The corrected author list is given above.

Publisher's Note Springer Nature remains neutral with regard to jurisdictional claims in published maps and institutional affiliations.

The original article can be found online at https://doi.org/10.1007/s13580-018-0113-0.

Young Hee Joung

yhjoung@jnu.ac.kr

1 Plant Molecular Biology Laboratory, School of Biological Sciences and Technology, Chonnam National University, Gwangju 61186, Korea

2 Department of Landscape Architecture, Planning and Management, Swedish University of Agricultural Sciences, Sundsvägen, 23053 Alnarp, Sweden

3 Department of Agronomy and Horticulture, University of Nebraska, Lincoln, NE 68583, USA

4 Department of Environmental Horticulture, Dankook University, Cheonan, Chungcheongnam-do, 31116, Korea

5 Agriculture and Life Sciences, Department of Forest Sciences, Seoul National University, Seoul 08826, Korea 